\title{
A randomized prospective study of extended tocopherol and pentoxifylline therapy, in addition to carbogen, in the treatment of radiation late effects
}

\author{
S Brennan, O Salib, C O'Shea and M Moriarty
}

St Luke's Hospital, Dublin, Ireland

\begin{abstract}
Purpose: pentoxifylline (PTX) and tocopherol (vitamin E) are antioxidants previously shown to be useful in combination in the treatment of late radiation induced toxicity. The purpose of this study was to investigate the benefit of combination therapy with carbogen pentoxifylline and tocopherol in the mitigation of late radiation effects. As the optimal duration of PTX and tocopherol treatment has not been fully established, we studied short versus extended treatment duration.
\end{abstract}

Methods: we conducted a phase II prospective randomized study of short versus prolonged treatment with pentoxifylline (800 mg) and tocopherol $(1000 \mathrm{IU})$ orally once daily in patients with grade three toxicity post-radical radiotherapy. In addition, all 18 patients received inhaled carbogen $\left(95 \% \mathrm{O}+5 \% \mathrm{CO}_{2}\right)$ over 90 minutes, five days/week, for three weeks. The primary end point was improved in maximum Lent-Soma toxicity scores.

Results: maximum Lent-Soma scores improved in six of the 18 patients (response rate 33\%). The proportion of patients responding to treatment in the prolonged treatment arm B was more than double than in the shorter arm A, but this did not reach statistical significance $(p=0.321)$. Two patients who had prolonged treatment (arm B) had complete resolution of their symptoms, which was maintained at two and three year follow-ups.

Conclusions: we recommend prolonged treatment for 12 months, with PTX and tocopherol in combination with carbogen therapy, in the management of late radiation effects.

Published: 09/06/2008

Received: 21/04/2008

ecancer 2008, 2:81 DOI: 10.3332/eCMS.2008.81

Copyright: (c) the authors; licensee ecancermedicalscience. This is an Open Access article distributed under the terms of the Creative Commons Attribution License (http://creativecommons.org/licenses/by/2.0), which permits unrestricted use, distribution, and reproduction in any medium, provided the original work is properly cited.

Competing Interests: The authors have declared that no competing interests exist.

Correspondence to S Brennan. Email: sinead.brennan@slh.ie 


\section{Introduction}

As cancer treatment outcomes improve, there is increased emphasis on reducing toxicity of treatment as part of an effort to broaden the therapeutic index of therapy. Late radiotherapy effects are a considerable source of symptomatic morbidity in survivors of cancer therapy. Although traditionally considered progressive and irreversible, there is now mounting evidence to support the potential reversibility and treatment of radiotherapeutic injury using antioxidant therapy [1,2].

Over the past decade, there have been several reports in support of tocopherol and pentoxifylline (PTX) in the treatment of late radiation effects $[1,2,3]$. Hyperbaric oxygen has also shown some efficacy in this area [4]. Carbogen is thought to act similarly to hyperbaric oxygen (HBO) by reversing tissue hypoxia and thus removing free radicals, which are implicated in the pathogenesis of late radiation effects [5].

The combination of PTX and tocopherol has yielded far greater and consistent results than the use of either agent alone [1]. We postulated that the addition of carbogen therapy to this combination would further enhance the modulation of radiationinduced normal tissue damage. The optimum duration of treatment has not been fully established, with trials continuing treatment for a variety of times from three to 36 months [2].

We conducted a phase II prospective randomized study, examining the benefit of extended compared to short-term use of PTX and tocopherol used in combination with carbogen therapy, in the management of radiation-induced normal tissue morbidity.

\section{Methods}

The study design involved a prospective, randomized trial of short versus prolonged treatment, with pentoxifylline and tocopherol in addition to inhaled carbogen (95\% O +5\% $\left.\mathrm{CO}_{2}\right)$. Carbogen was inhaled via a close-fitting face mask, with a oneway valve and closed breathing system over 90 minutes/day, five days/week, for three weeks. Patients were randomized to either $\operatorname{arm} A$, which consisted of a short three-week course of pentoxifylline and tocopherol, or arm $B$, which was a prolonged 12-month course. Pentoxifylline was administered at a dose of $800 \mathrm{mg}$ and tocopherol at a dose of $1000 \mathrm{IU}$. Both were taken orally once daily, and the same dose was used in both arms of the study.
Patients with grade 3 (Lent-Soma) [6] toxicity, post-radical radiotherapy, for a variety of cancer primaries, were eligible for the trial. Inclusion criteria required that patients had received radical radiotherapy that consequently caused grade 3 side effects within the irradiated area. Patients were accrued as a consecutive presenting sample. Eighteen patients with significant late morbidity post-radical radiation therapy were randomized to one of the two study arms, using envelope randomization (see Figure 1).

Figure 1 depicts the randomization process. All 18 patients in the study received carbogen therapy $\left(95 \% \mathrm{O}+5 \% \mathrm{CO}_{2}\right)$ over 90 minutes, five days/week, for three weeks, which was inhaled via a close-fitting face mask, with a one-way valve and closed breathing system, over 90 minutes daily five days/week, for three weeks. Patients were randomized to either arm A, which consisted of a short three-week course of pentoxifylline and tocopherol, or arm B, which was a prolonged 12-month course. Pentoxifylline was administered at a dose of $800 \mathrm{mg}$ and tocopherol at a dose of $1000 \mathrm{IU}$. Both were taken orally once daily, and the same dose was used in both arms of the study.

We initially planned to include 30 patients in the trial. However, due to slow accrual the study was closed after 18 patients. One of the reasons for slow accrual was patients' reluctance to attend the hospital day ward 15 times over a three-week period for carbogen therapy. The study commenced in March 2001 and randomization completed in August 2003. The mean time period between completion of radiotherapy and study enrolment was 58.6 months (range 11-224 months). Of the 18 patients, three were male and 15 were female. The mean age was 59.9 years (range 22-82 years). The group included eight patients with breast cancer, four patients with head and neck cancer, four patients with gynaecological malignancies, one patient with gastro-intestinal malignancy and one case of Bowen's disease of the skin. Radiation-induced toxicities included subcutaneous fibrosis lymphoedema, post-radiation cystitis and increased bowel frequency (see Table 1).

The severity of radiation late effects was assessed using the Lent-Soma (late effect normal tissues subjective objective management and analytic) scale, defined by the Radiation Therapy Oncology Group and the European Organisation for the Research and Treatment of Cancer [6]. Clinical assessment of late side effects, recorded using Lent-Soma scales, was used as the primary end point. Maximum Lent-Soma scores were recorded at baseline and at four, eight and 12 months posttreatment. One patient did not receive any treatment as she was 


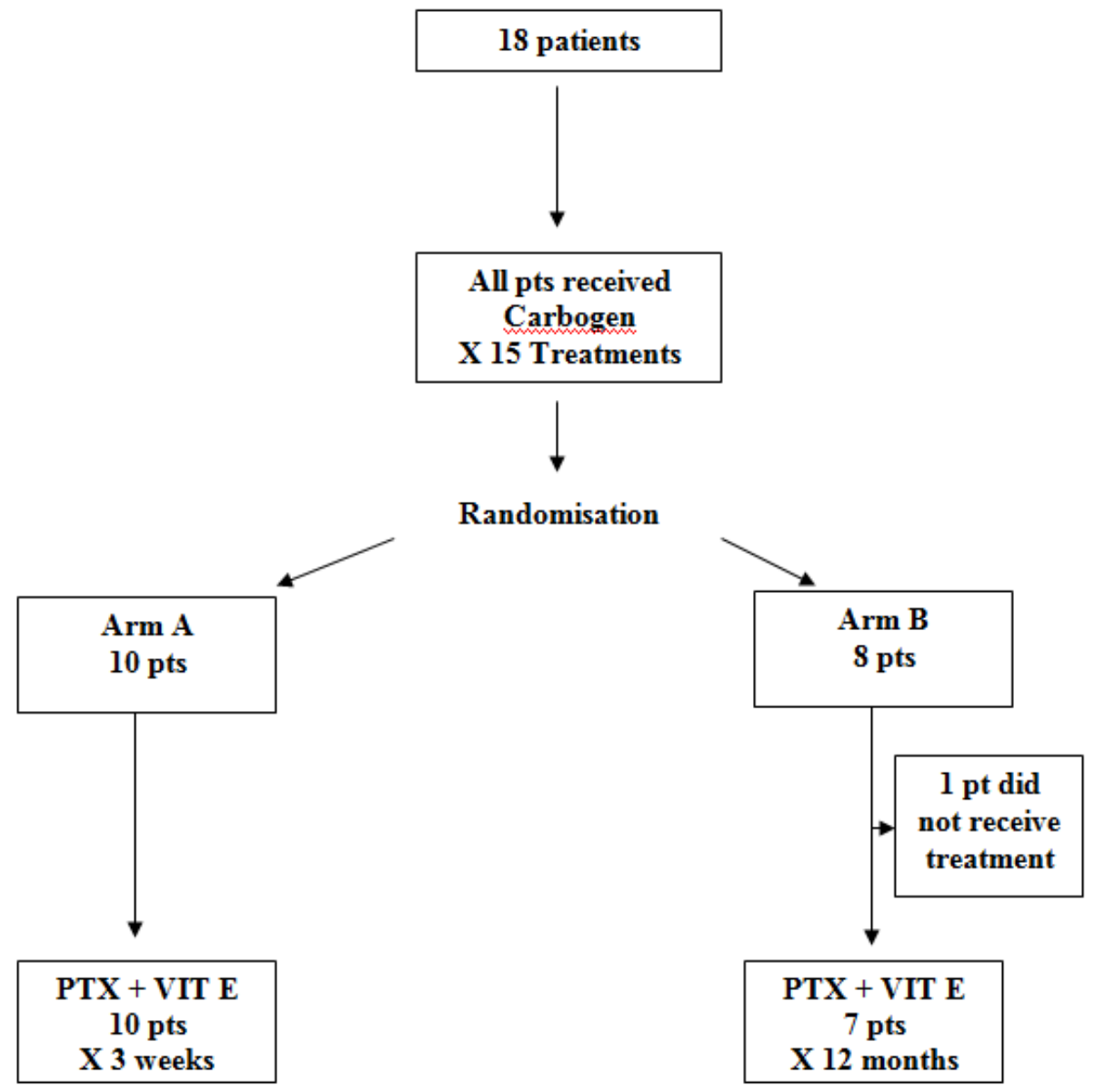

Pts: Patients

PTX: Pentoxifylline

VIT E: Vitamin E/tocopherol

Figure 1: The randomization process

hospitalized for treatment of an infection. Intention to treat analysis was performed. Patient's data were entered onto EXCEL and transferred to Minitab statistical software for statistical analysis. We compared the overall proportions of responders in each arm of the trial, using Fisher's exact test with a significance level of $p=0.05$.

Written information consent was obtained from all patients. Ethical approval was obtained from St Lukes Ethics and Medical Research Committee.

\section{Results}

All patients tolerated carbogen therapy extremely well. Three patients experienced nausea due to pentoxifylline, one of whom discontinued treatment. The other two patients improved on commencing domperidone medication. We subsequently adopted a policy of administering five days of domperidone to all patients routinely at the start of therapy. Following this there were no further reports of nausea.

Of the 17 patients who received treatment, six patients had improvement in their symptoms (see Tables 1 and 2 ), thus 
Table 1: Overall results

\begin{tabular}{|c|c|c|c|c|c|c|c|c|}
\hline PT & $\begin{array}{l}\text { Age } \\
\text { (yrs) }\end{array}$ & Sex & Diagnosis & $\begin{array}{c}\text { RT } \\
\text { Dose /\# }\end{array}$ & $\begin{array}{c}\text { Side Effect } \\
\text { Gr } 3\end{array}$ & $\begin{array}{c}\text { Time } \\
\text { post } \\
\text { RT } \\
\text { (mts) }\end{array}$ & $\begin{array}{c}\text { Arm A- } \\
\text { Improved } \\
\text { Y/N- } \\
\text { onset }\end{array}$ & $\begin{array}{c}\text { Arm B- } \\
\text { Improved } \\
\text { Y/N- } \\
\text { onset }\end{array}$ \\
\hline 1 & 51 & $\mathrm{~F}$ & Rectum & $45 \mathrm{~Gy} / 22 \#$ & Diarrhoea & 52 & No & \\
\hline 2 & 50 & $\mathrm{~F}$ & Breast & $45 \mathrm{~Gy} / 20 \#$ & Fibrosis & 12 & No & \\
\hline 3 & 53 & $F$ & Breast & $45 \mathrm{~Gy} / 20 \#$ & Fibrosis & 45 & No & \\
\hline 4 & 64 & $\mathrm{~F}$ & CBU & $\begin{array}{c}30 \mathrm{~Gy} / 15 \# \\
+20 \mathrm{~Gy} \\
\mathrm{MDR}\end{array}$ & $\begin{array}{c}\text { Dysuria, } \\
\text { PV bleeding }\end{array}$ & 130 & & $\begin{array}{l}\text { Yes }(4 / 12) \\
\text { Gr } 3 \rightarrow \mathrm{Gr} 2\end{array}$ \\
\hline 5 & 42 & $\mathrm{~F}$ & $\begin{array}{l}\text { Recurrent } \\
\text { cervix }\end{array}$ & $\begin{array}{c}45 \mathrm{~Gy} / 25 \# \\
+20 \mathrm{~Gy} \\
\mathrm{MDR}\end{array}$ & $\begin{array}{c}\text { Diarrhoea, } \\
\text { Dysuria }\end{array}$ & 102 & $\begin{array}{l}\text { Yes }(2 / 12) \\
\text { Gr } \underset{1}{3 \rightarrow} \mathrm{Gr}\end{array}$ & \\
\hline 6 & 33 & $\mathrm{~F}$ & Cervix & $\begin{array}{c}50 \mathrm{~Gy} / 2 \# \\
\text { MDR }\end{array}$ & $\begin{array}{c}\text { Urinary } \\
\text { Incontinence }\end{array}$ & 72 & & $\begin{array}{l}\text { Yes }(2 / 12) \\
\text { Gr3 } \rightarrow \text { Gr2 }\end{array}$ \\
\hline 7 & 48 & $\mathrm{M}$ & Tonsil & $68 \mathrm{~Gy} / 34 \#$ & Odynophagia & 10 & & No \\
\hline 8 & 22 & $\mathrm{M}$ & Nasopharynx & $68 \mathrm{gy} / 34 \#$ & Fibrosis & 17 & No & \\
\hline 9 & 71 & $\mathrm{~F}$ & Breast & $45 \mathrm{~Gy} / 20 \#$ & Fibrosis & 32 & No & \\
\hline 10 & 82 & $\mathrm{~F}$ & Breast & $\begin{array}{c}40 \mathrm{~Gy} / 20 \# \\
+ \text { retreat } \\
30 \mathrm{~Gy} / 6 \# \\
1 \# \text { per wk }\end{array}$ & Lymphedema & 17 & No & \\
\hline 11 & 67 & $\mathrm{~F}$ & Ovarian & $45 \mathrm{gy} / 25 \#$ & Diarrhoea & 116 & No & \\
\hline 12 & 67 & $\mathrm{~F}$ & $\begin{array}{c}\text { Bilateral } \\
\text { Breast }\end{array}$ & $\begin{array}{c}37 \mathrm{~Gy} / 10 \# \\
\text { L breast } \\
37.4 \mathrm{~Gy} / 11 \# \\
\text { R Breast }\end{array}$ & Fibrosis & 224 & No & \\
\hline 13 & 56 & $\mathrm{~F}$ & Breast & $45 \mathrm{~Gy} / 20 \#$ & Pain & 60 & & No \\
\hline 14 & 53 & F & Breast & $45 \mathrm{~Gy} / 20 \#$ & Fibrosis & 39 & $\begin{array}{l}\text { Yes }(2 / 12) \\
\text { Gr } 3 \rightarrow \text { Gr } 1\end{array}$ & \\
\hline 15 & 68 & $\mathrm{~F}$ & NHL & $36 \mathrm{~Gy} / 18 \#$ & Pain & 60 & & NO TX \\
\hline 16 & 59 & M & Tonsil & $60 \mathrm{~Gy} / 30 \#$ & Dysphagia & 24 & & No \\
\hline 17 & 75 & $\mathrm{~F}$ & Bowens Skin & $35 \mathrm{~Gy} / 5 \#$ & Fibrosis & 11 & & $\begin{array}{l}\text { Yes }(5 / 12) \\
\text { Gr } 3 \rightarrow \text { Gr } 0\end{array}$ \\
\hline 18 & 46 & $F$ & Breast & $\begin{array}{c}42.75 \mathrm{~Gy} / \\
25 \#\end{array}$ & $\begin{array}{c}\text { Pain } \\
\text { Fibrosis }\end{array}$ & 32 & & $\begin{array}{l}\text { Yes }(7 / 12) \\
\text { Gr } 3 \rightarrow \mathrm{Gr} 0\end{array}$ \\
\hline
\end{tabular}

MDR - Medium Dose Rate Brachytherapy delivered @ 140 - 160 cGy/Hr - Selectron 
Table 2: Proportion of patients responding to treatment according to diagnosis and treatment arm

\begin{tabular}{|c|c|c|c|c|c|}
\hline & \multicolumn{5}{|c|}{ No. of Responders / No. of Pts Treated } \\
\hline Arm & All & Breast & Pelvis & H+N & Skin \\
\hline A & $2 / 10$ & $1 / 6$ & $1 / 3$ & $0 / 1$ & - \\
\hline B & $4 / 8$ & $1 / 2$ & $2 / 2$ & $0 / 3$ & $1 / 1$ \\
\hline Both arms & $6 / 18$ & $2 / 8$ & $3 / 5$ & $0 / 4$ & $1 / 1$ \\
\hline
\end{tabular}

Table 3: Results of Fisher's exact test for comparison of proportions responding in each arm, using frequencies in frequency

\begin{tabular}{|c|c|c|c|}
\hline & Response & Response & Response \\
\hline Arm & Yes & No & All \\
\hline A & 2 & 8 & 10 \\
\hline B & 4 & 4 & 8 \\
\hline All & 6 & 12 & 18 \\
\hline
\end{tabular}

giving an overall response rate of $33 \%$. The overall proportions responding in each arm were $2 / 10$ in arm A versus 4/8 in arm $B$. Although the proportion responding to treatment in the prolonged treatment arm $B$ was more than double ( 0.5 versus 0.2 ) than in the shorter arm A, (see Table 3 ) the difference is not statistically significant $(p=0.321)$.

The median time to onset of response was 3.5 months with a range of 2-7 months (see Table 1). Of the two patients in the shorter treatment group A arm who responded, the first (patient 5) had dysuria and diarrhoea, which showed an initial improvement from grade 3 to grade 2 after two months, but her symptoms subsequently recurred. She was later re-treated with 15 sessions of carbogen over a three-week period, and 12 months of pentoxifylline (800 mg) and tocopherol (1000 IU). On re-treatment, with the extended regimen, her dysuria reduced to grade 1 and this benefit was maintained for over one year. The second patient (patient 14) had fibrosis post-breast radiotherapy, which improved from grade 3 to grade 2 toxicity at two months, but then subsequently refused further follow-up for personal reasons.

Four of the eight patients in the prolonged 12-month treatment arm B demonstrated response to treatment. Two of these patients with grade 3 fibrosis (patients 17 and 18 in Table 1) had complete resolution of their symptoms, and this benefit was maintained for two and three years, respectively. The third patient (patient 6) had urinary incontinence, which improved from grade 3 to grade 2 toxicity, and this was maintained for one year. The final patient (patient 4) had dysuria and PV bleeding, which improved from grade 3 to grade 2, but this benefit was not maintained.

\section{Discussion}

Late radiation effects are progressive in nature and have a significant negative impact on quality of life in long-term cancer survivors. In our study, 33\% of patients had an improvement in their symptoms, which otherwise would have remained unchanged or perhaps even worsened. We feel that the combination of carbogen with PTX and tocopherol represents an effective treatment, especially as treatment was well tolerated, cost-effective and no established alternative currently exists. Although nausea was a side effect of the PTX treatment, this responded well to treatment with domperidone.

Late radiotherapy effects are a debilitating, chronic, adverse effect of treatment and have traditionally been considered both progressive and irreversible. In such circumstances, prevention 
is often the best cure and limiting both dose and volume to irradiated tissues is imperative in reducing the incidence and extent of such effects. Despite these efforts, there is much individual variation and unpredictability in regard to development of late radiotherapy side effects. Treatment intensification is becoming increasingly popular both in terms of concurrent chemotherapy and intensified fractionation schemes. However, this will likely be at the expense of increased incidence and severity of late radiotherapeutic injury.

The irreversibility of late radiation effects has been disputed for some time $[1,2]$. Radiation induced injury is traditionally thought to be a chronic progressive process due to mitotic cell death in tissues and reduction in the number of surviving clonogens. However, in recent times, there is increasing evidence to suggest that this process is not entirely irreversible [3], and that late radiation effects are due to a much more dynamic interactive process between multiple cell types, including parenchymal and vascular cells. This is enhanced by secretion of a cascade of pro-inflammatory and fibrogenic cytokines [7].

As an anticytokine pentoxifylline is thought to reverse this process [8]. PTX is a haemorheologic methylxanthine derivative initially developed to improve blood viscosity and microcirculatory disorders. Alpha tocopherol is a powerful antioxidant that protects membrane phospholipids from oxidative damage [9] and acts as a scavenger of reactive oxygen species. The precise mechanism of action of these agents is not yet known. Both PTX and tocopherol are antioxidants previously shown to be of superior benefit in combination in the treatment of late radiation effects [3]. In a clinical trial, Delanian et al reported objective response rates of $53 \%$ at six months, using this combination [10], that is regression of radiation-induced fibrosis surface area. Our study reports a response rate of $33 \%$, giving further confirmation of the efficacy of this combination in the treatment of late radiotherapy effects.

Hyperbaric oxygen therapy (HBOT) has been used to treat several medical conditions, including necrotising fasciitis and osteoradionecrosis [11]. It has been used in radiation oncology, as both a radiosensitiser and also as a treatment of late radiation effects. It is thought to stimulate angiogenesis and improve tissue oxygenation, resulting in healing of damaged soft tissue bone and cartilage. In a small placebo controlled prospective trial, Carl et al reported significant improvements in pain and swelling in 44 patients with late radiation induced injury post-radiotherapy for breast cancer [4]. In another retrospective trial of 75 patients with osteoradionecrosis, $81 \%$ of patients responded to HBOT [12]. The Consensus Conference, led by the European Society for Therapeutic Radiology and Oncology and the European Committee for Hyperbaric Medicine, recommended prospective collection of toxicity data and setting up of multi-centre randomized controlled trials to obtain higher levels of evidence for indications of HBOT [11].

Carbogen is thought to work in a similar manner to HBOT. In a study by Collet $e t$ al, there was no difference in results between hyperbaric oxygen and slightly pressurized air, and the two treatments were considered equally effective [13]. Powel et al conducted a study that showed breathing carbogen $\left(5 \% \mathrm{CO}_{2}\right.$ and $95 \% \mathrm{O}$ ) increased tumour oxygenation, by comparing $\mathrm{pO}_{2}$ measurements pre- and post-carbogen breathing [5]. In our study, carbogen therapy was tolerated well. As patients were not randomized for carbogen therapy, it is not possible to assess the relative contribution of carbogen to the results obtained.

The optimum duration of treatment has not been fully established, with other trials continuing treatment for various durations from three to 36 months [2]. This trial showed a trend towards better response with more prolonged treatment, with three of the four patients in the prolonged treatment arm B, maintaining their improvements for 1-3 years. Also, the proportion responding to treatment in the prolonged treatment arm B was more than double that in the shorter arm A. This result was not statistically significant, possibly due to the small number of patients in the study and also the combination of patients with a variety of late toxicities in this study. However, this finding is consistent with other studies [2] and gives further confirmation of the benefit of prolonged treatment. We recommend clinical use of these agents with treatment duration of at least 12 months.

In addition, there is evidence for rebound effects in this study if the treatment period is too short. One patient had a recurrence of her symptoms on completion of the shorter three-week course, suggesting a rebound effect. In a study of response kinetics in long-term treatment with PTX and tocopherol, Delanian et al also reported a rebound effect due to discontinuation of treatment in three of seven patients in the shorter treatment arm [2]. The same patient in our trial had an even more substantial improvement from grade 3 to grade 1 toxicity (diarrhoea) on re-treatment with this therapy for 12 months, thus giving further basis for more prolonged therapy.

This was a heterogeneous group of patients indicating the broad scope of potential benefit with this treatment. Other groups have reported improvement in $71 \%$ of patients with proctitis and enteritis with combination PTX and tocopherol therapy [14]. Gothard et al have shown significant 
improvements in Lent-Soma scores for genito-urinary dysfunction and proctitis with this combination [15]. This combination has also been studied in osteoradionecrosis [16], and pentoxifylline has been shown to be of benefit in radiationinduced trismus [17] and lung toxicity in patients with breast and lung cancer [18].

However, several studies have examined the use of PTX and tocopherol specifically in the management of radiation-induced subcutaneous fibrosis [1,2 and 11]. We would support this as, in our study, two patients with radiation-induced fibrosis both had complete resolution of their symptoms on the prolonged treatment arm B. These improvements were maintained for two and three years, respectively, and thus they represent the most significant responses in our trial. There has been much progress in understanding the molecular mechanisms and pathophysiology involved in radiation injury, and this should be used to model therapeutic strategies for this disease. In the era of targeted therapies, agents such as angiotensin-converting enzyme (ACE) inhibitors and angiotensin receptor type I antagonists, which target the renin-angiotensin system, are proving to be of benefit in modulating late radiation effects in kidney and lung tissues [19]. These tissues are known to possess an intrinsic renin-angiotensin system. ACE inhibitors are also being studied in radiation-induced lung injury in the RTOG 0123 study [20]. Thus, it may be possible to direct the use of different aetiology-based treatments to tissue-specific late radiation reactions. In this instance, we would suggest that combination therapy with carbogen PTX and tocopherol might be of greater benefit in the management of radiation-induced subcutaneous fibrosis. Future studies with this therapeutic combination should involve sub-group analysis for late radiation effects in different tissue types, as perhaps not all radiationinduced toxicity will respond in a similar manner.

Conflict interests: There are no conflicts of interest to declare.

Acknowledgement: We would like to acknowledge the contribution of Dr Tom O'Hara, PhD, C.Stat., in the statistical analysis of this paper. 


\section{References}

1. Delanian S, Porcher R, Balla-Mekias S and Lefaix JL (2003) Randomised placebo controlled trial of combined pentoxifylline and tocopherol for regression of superficial radiation induced fibrosis J Clin Oncol $21 \quad 13$ 2545-50 PMID 12829674 doi: 10.1200/JCO.2003.06.064

2. Delanian S, Porcher R, Rudant J and Lefaix JL (2005) Kinetics of response to long-term treatment, combining pentoxifylline and tocopherol in patients with superficial radiation induced fibrosis J Clin Oncol 2334 8570-9 PMID 16260695 doi: 10.1200/JCO.2005.02.4729

3. Lefaix JL, Delanian S, Vozenin MC, Leplat JJ, Tricaud Y and Martin M (1999) Striking regression of subcutaneous fibrosis induced by high doses of gamma rays using a combination of pentoxifylline and alpha-tocopherol: an experimental study Int J Radiat Oncol Biol Ph 434 839-47 $\underline{\text { PMID } 10098440} \underline{\text { doi:10.1016/S0360-3016(98)00419-2 }}$

4. Carl UM, Feldmeier JJ, Schmitt G and Hartmann KA (2001) Hyperbaric oxygen therapy for late sequelae in women receiving radiation after breast conserving surgery Int $\mathbf{J}$ Radiat Oncol Biol Phys 494 1029-31 PMID 11240244 doi: 10.1016/S0360-3016(00)01515-7

5. Powell ME, Collingridge DR, Saunders MI, Hoskin PJ, Hill SA and Chaplin DJ (1999) Improvement in human tumour oxygenation with carbogen of varying carbon dioxide concentrations Radiother Oncol 5022 167-71 PMID 10368040 doi: 10.1016/S0167-8140(98)00123-6

6. Powell ME, Collingridge DR, Saunders MI, Hoskin PJ, Hill SA and Chaplin DJ (1999) LENT SOMA Tables Radiother Oncol 50 167-71 PMID 10368040 doi: 10.1016/S01678140(98)00123-6

7. Rubin $\mathrm{P}$, Johnston $\mathrm{C}$, Williams JP, McDonald $\mathrm{S}$ and Finkelstein JN (1995) A perpetual cascade of cytokines post-irradiation leads to pulmonary fibrosis Int $\mathbf{J}$ Radiat Oncol Biol Phys 331 99-109 PMID 7642437

8. Marques LJ, Zheng N, Poulakis J, Guzman J and Costabel $U$ (1999) Pentoxifylline inhibits TNF alpha production from human alveolar macrophages Am J Respir Crit Care Med 1592 508-11 PMID 9927365

9. Baillet F (1997) Alpha tocopherol treatment of radio-fibrosis post brachytherapy for breast cancer Radiother Oncol 43 S3 (Suppl 1) Abstract

10. Delanian S, Balla-Mekias S and Lefaix JL (1999) Striking regression of chronic radiotherapy damage in a clinical trial of combined pentoxifylline and tocopherol J Clin Oncol 17 10 3283-90 PMID 10506631
11. Pasquier D, Hoelscher T, Schmutz J, Dische S, Mathieu D, Baumann M and Lartigua E (2004) Hyperbaric oxygen therapy in the treatment of radio-induced lesions in normal tissues: a literature review Radiother Oncol 721 1-13 $\underline{\text { PMID 15236869 doi: 10.1016/j.radonc.2004.04.005 }}$

12. Bui QC, Lieber M, Withers HR, Corson $K$, van Rijnsoever M and Elsaleh $H$ (2004) The efficacy of hyperbaric oxygen therapy in the treatment of radiation induced late side effects Int J Radiat Oncol Biol Phys 603 871-8 PMID 15465205

13. Collet JP, Vanasse M, Marois P, Amar M, Goldberg J, Lambert J, Lassonde M, Hardy P et al (2001) Hyperbaric oxygen for children with cerebral palsy: a randomised multicentre trial Lancet 3579256 582-6 PMID 11558483 doi: 10.1016/S0140-6736(00)04054-X

14. Hille A, Christiansen $\mathrm{H}$, Pradier $\mathrm{O}$ et al (2005) Effect of pentoxifylline and tocopherol on radiation proctitis/enteritis Strahlenther Onkol 1819 606-14 PMID 16170489 doi: 10.1007/s00066-005-1390-y

15. Gothard L, Cornes P, Brooker S et al (2005) Phase II study of vitamin $E$ and pentoxifylline I patients with late side effects of pelvic radiotherapy Radiother Oncol 753 334-41 PMID 16086914 doi: 10.1016/j.radonc.2005.02.002

16. Delanian S, Depondt J and Lefaix JL (2005) Major healing of refractory mandible osteoradionecrosis after treatment combining pentoxifylline and tocopherol: a phase II trial Head Neck 272 114-23 PMID 15641107 doi: 10.1002/ hed.20121

17. Chua D, Lo C, Yuen J and Foo YC (2001) A pilot study of pentoxifylline in the treatment of radiation induced trismus Am J Clin Oncol 24 366-9 PMID 11474263 doi: 10.1097/00000421-200108000-00010

18. Ozturk B, Egehan I, Atavci S and Kitapci M (2004) Pentoxifylline in prevention of radiation-induced lung toxicity in patients with breast and lung cancer: a double blind randomized trial Int J Radiat Oncol Biol Phys 581 213-9 PMID 14697441 doi: 10.1016/S0360-3016(03) 01444-5

19. Robbins ME and Diz DI (2006) Pathogenic role of the reninangiotensin system in modulating radiation-induced late effects Int J Radiat Biol Phys 641 6-12 PMID 16377409

20. Philadelphia radiation Therapy Oncology Group (2004) RTOG-0123: A Phase II Randomised Trial With Captopril in Patients Who Have Received Radiation Therapy \pm Chemotherapy for Stage II-IIIB Non Small Cell Lung Cancer Stage 1 Central Non-Small Cell Lung Cancer or Limited-Stage Small Cell Lung Cancer 